\title{
An analysis of users' preferences on learning management systems: a case on German versus Spanish students
}

\author{
Hasan Tinmaz ${ }^{1}$ and Jin Hwa Lee $2^{2^{*}}$
}

\author{
*Correspondence: jlee4986@yahoo. \\ com \\ ${ }^{2}$ Global Healthcare Management, \\ Sol International School, Woosong \\ University, 171 Dongdaejeon-ro, \\ Dong-gu, Daejeon 34606, South \\ Korea \\ Full list of author information is \\ available at the end of the article
}

\begin{abstract}
The recent advancements in information and communication technologies have altered instructional contexts and re-shaped them into smart learning environments. One of the most common practices of these environments are learning management systems (LMS) where the learners and instructors utilize a software platform to fulfill, support and manage instructional activities around predefined objectives. Successful implementations of LMS have brought a variety on its usage from different cultures, genders, age groups or schooling levels. Hence, this study focuses on understanding the role of culture on LMS design, in along with the effects of gender, age and school year variables. The study participants were German $(n=83)$ and Spanish $(n=83)$ university students attending a fully online course offered by a South Korean university. At the end of the course, the students were asked to fulfill a survey on effective LMS design by pointing which features of LMS were more important for them. The survey included twenty questions on four major design factors; content management (six items), ease of use (five items), communication within LMS (four item) and screen design (five items). The dataset was analyzed by non-parametric statistical techniques around four variables on four dimensions (and their related survey questions). The most important result was insufficiency of one unique LMS design for all students which demonstrates the necessity of student demographics tailored smart systems. Additionally, age and gender variables were not making significant differences on LMS design as much as culture and school year variables. The study also revealed that while German students would appreciate goal-oriented individual learning, Spanish students would value process-oriented group learning with active communication. Furthermore, many features of LMS were highly valued by the freshman students more than other levels. The paper discusses these variables with possible explanations from the literature and depicts implementations for future design practices.
\end{abstract}

Keywords: Culture, Learning management systems, LMS, Smart learning, Spanish, German

\section{Introduction}

Teaching and learning processes have continuously evolved with technological advances. Correspondingly, the rapid development of information and communication technologies has shaped traditional classrooms into smart learning environments. For

(c) The Author(s). 2020 Open Access This article is licensed under a Creative Commons Attribution 4.0 International License, which permits use, sharing, adaptation, distribution and reproduction in any medium or format, as long as you give appropriate credit to the original author(s) and the source, provide a link to the Creative Commons licence, and indicate if changes were made. The images or other third party material in this article are included in the article's Creative Commons licence, unless indicated otherwise in a credit line to the material. If material is not included in the article's Creative Commons licence and your intended use is not permitted by statutory regulation or exceeds the permitted use, you will need to obtain permission directly from the copyright holder. To view a copy of this licence, visit http://creativecommons.org/licenses/by/4.0/. 
instance, sharing learning materials online has enabled the learners to study whenever and wherever they want. Online attendance marking systems have also dramatically reduced the amount of time spent by the instructors to check their students' attendance and thus increased the actual teaching and learning time. Moreover, the assignments or examinations can also be delivered online with appropriate instructions and feedback to support learning outside of scheduled classes. Likewise, there are many other ubiquitous combinations of pedagogical practices supported or facilitated with recent technologies.

Due to increasing number of available smart learning features, it has become indispensable to manage these features for effective and organized instructional processes. Currently, it is commonly seen that educational institutes operate their own Learning Management Systems (LMS) and provide various online smart learning features for a diverse group of students. An LMS is known as a web-based system that possesses an extensive range of pedagogical and course administration tools (Yakubu, 2019). Through these educational tools, LMS can facilitate group chats, discussions, document sharing, assignment submission, quizzes, grading and course evaluations (Bove, \& A., \& Conklin, S., 2020). Moreover, LMS has a potential to serve students with diverse backgrounds including culture, age or gender.

Previous studies have focused on identifying various learning features of LMS that can influence students' learning outcomes. However, it seems that the results of previous studies were controversial with inconsistent learning outcomes of the students. One possible reason can be due to the lack of thorough understanding on students' learning preferences, needs and diverse backgrounds. As the essence of an LMS is to facilitate self-regulated learning (Douglas \& Alemanne, 2007), there is a need for analyzing and understanding users' preferences when applying LMS in educational contexts which will serve various learning needs of the students.

As such, this study aims to analyze key factors that can influence users' preferences on LMS use and gain a deeper understanding of how to maximize the learning outcomes through LMS by considering four essential independent variables; culture, gender, age and school years. The results of this study will contribute to a successful implementation of smart learning in class.

\section{Literature review}

The existing learning management systems literature has identified four major factors that need to be considered for successful implementation of LMS in order to fulfill students' learning needs and expectations. In this part, four major factors which were yielded from the conclusions of the existing literature review were elaborated. These four factors which are relevant with LMS user experiences are culture, gender, age, and school year.

\section{Cultural factor}

When the researchers conducted literature review and analysis, it was unfolded that previous studies highlighted the importance of cultural factor in online learning. According to Hunt and Tickner (2015), culture is defined as “...a complex and multidimensional construct that represents the shared values, beliefs, and basic assumptions 
of groups of people. It includes elements such as language, customs, social behavior, and religion, and it influences how individuals relate to the world..." (p. 27). One of the most widely used models for understanding characteristics of cultural behaviors was developed by Hofstede (1986). In this model, he highlighted four dimensions of cultural behaviors or characteristics; 'small versus large power distance', 'individualism versus collectivism', 'masculinity versus femininity', and 'tolerance of uncertainty and ambiguity versus uncertainty avoidance'.

First of all, power distance is defined as "the extent to which the less powerful members of institutions and organizations within a country expect and accept that power is distributed unequally" (p. 61) (Hofstede, Hofstede, \& Minkov, 2010). For example, learning characteristics in high power distance cultures are more oriented towards one-way, directive, and instructor-based learning (Swierczek \& Bechter, 2010). The second dimension, individualism versus collectivism, as mentioned by Mercado, Parboteeah, and Zhao (2004), means "the tendency of members of a society to act as individuals or members of groups, and to which a culture values individual versus collective achievement or well-being" ( $\mathrm{p}$. 185). It can be seen that individualistic culture is more results oriented whereas collective culture is more consensus and discussion oriented (Swierczek \& Bechter, 2010).

In terms of the third dimension, masculinity versus femininity, a masculine culture shows clearly distinct emotional gender roles for men and women whereas feminine culture has overlapped emotional gender roles (Hofstede et al., 2010). Hence it seems that the learning characteristics in masculine society are achievement and competition focused rather than being affiliation oriented (Swierczek \& Bechter, 2010). Lastly, uncertainty avoidance is defined as "the extent to which the members of a culture feel threatened by ambiguous or unknown situations" (p. 191) (Hofstede et al., 2010). With high uncertainty avoidance, guided and structured learning is preferred over independent and open-ended learning (Swierczek \& Bechter, 2010).

Since our study involves German and Spanish students, their cultural differences were reviewed by using the four-dimensional model of Hofstede (Hofstede et al., 2010). It was noticed that Germany is a less power distant country than Spain and their relative power distance scores were 35 and 57 respectively. Thus, it is expected that Spanish students are more familiar with a hierarchical learning environment than German students. In terms of individualism versus collectivism, Germany and Spain obtained individualism scores of 67 and 51 respectively showing their different cultural views on individual versus group. It is expected that German students are more oriented towards individual learning and achievement. On the other hand, Spain's score was the second lowest among the European countries reflecting higher cultural tendency towards collectivism. When masculinity scores are compared, Germany appears to be a masculine society while Spain is a feminine society with relative scores of 66 and 42 respectively. It implies that German students value high performance and competition-based learning whereas Spanish students prefer harmony and non-competitive learning. Finally, uncertainty avoidance scores for both countries seem generally higher than the average. The relative scores for Germany and Spain were 65 and 86 respectively. As Spain scored higher than Germany, it is predicted that Spanish students will be more reluctant to experience changes, ambiguities, and undefined situations in learning.

In addition to identifying learners' characteristics, the four-dimensional model of Hofstede can be also used to analyze LMS acceptance levels in educational institutes. 
For example, Asunka (2016) identified cultural factors responsible for low LMS acceptance levels of university faculty members. Through a participatory action research approach, the study engaged 10 faculty members for one semester. Among the four cultural dimensions of Hofstede's model, 'power distance' was identified as the most influencing factor followed by 'individualism versus collectivism' and 'uncertainty avoidance'. Although this study applied the Hofstede's model on instructors rather than students, it highlighted significance of cultural factors in LMS implementation. In addition, Tarhini, Hone, Liu, and Tarhini (2017) revealed that these four cultural dimensions play an important role in students' technology acceptance level by influencing subjective norms. The study collected data from 569 undergraduate and postgraduate students in Lebanon using e-learning tools.

Although the Hofstede's model was not directly applied, previous studies have also reported the impact of cultural factors on students' learning performance and behaviors. For example, Liu, Liu, Lee, and Magjuka (2010) investigated the impact of cultural differences on international students' learning performance. This study involved international students from India, China, and Russia who attended an online Master of Business Administration (MBA) program. Through this study, cultural factors including language, communication tool use, plagiarism, time zone differences, and a lack of multicultural contents were suggested as potential barriers for online learning that can affect students' learning performance. Similarly, cultural influences on learning behaviors were reported by Swierczek and Bechter (2010). Their study performed qualitative and quantitative analyses of e-learning behaviors of participants from South Asia, East Asia, and Europe. The study results indicated that European students tend to be individualistic and prefer learning by induction whereas South and East Asian students value affiliation and avoid high uncertainty in learning. In addition, East Asian students appeared to be more active and involved in e-learning. The study suggested several cultural factors responsible for different learning behaviors which included language, technology, the role of instructor, and the level of interaction required. In other words, LMS designing and implementation should cater for various learning needs of students that can arise due to different cultural backgrounds.

The existence of cultural factors often creates cultural barriers to limit the potentials of online learning facilitated by LMS. Thus, it is inevitable to identify possible solutions to overcome these barriers. As mentioned above, Asunka (2016) reported existence of cultural barriers among the instructors that can trigger their anxiety, uncertainty, and indifference towards LMS usage. However, identification of responsible cultural dimensions, regular discussions, and monitoring the outcomes of LMS implementation throughout the semester made positive changes in the instructors' views on LMS. It can be noted that identification of cultural variables, along with other possible variables, plays a critical role in the outcomes of LMS usage. To overcome cultural barriers, Parrish and Linder-VanBerschot (2010) investigated the influence of cultural dimensions in online learning, which involved social relationships, epistemological beliefs, and temporal perceptions. Using the cultural dimensions of learning framework as a diagnostic tool, possible solutions to overcome the challenges of multicultural learning were suggested as increased awareness, culturally sensitive communication, modified instructional design processes, and efforts to accommodate critical cultural differences. 


\section{Gender factor}

Apart from cultural differences, another important factor drawn from the literature review conclusions is the gender difference. Previous studies have reported different characteristics of male and female students involved in online learning. According to a study conducted by Cuadrado-García, Ruiz-Molina, and Montoro-Pons (2010), male and female students showed significant differences in the assessment and use of elearning activities. This study involved a bilingual e-learning project between two European universities. The study revealed that female students achieved better final grades than male students with significantly higher resource views on LMS. Furthermore, male students needed more assistance with the online software. These results also support the argument from Bruestle et al. (2009) who stated that e-learning favors female students due to its flexible and interactive learning approach. Gender difference is also evident in general internet usage patterns (Lim \& Meier, 2011). Out of four general internet use reasons; 'social networking', 'personal knowledge', 'formal learning', and 'entertainment', the males focused more on entertainment whereas the females were engaged with social networking. This corresponds to the study results obtained by Adamus, Kerres, Getto, and Engelhardt (2009). Their study indicated that female university students focused more on communication and cooperation with openness to other's proposals. After all, such characteristics of female students highly influenced their learning outcomes in an online training program.

On the other hand, the impact of gender difference was questioned by several studies. Astleitner and Steinberg (2005) reported that gender differences in webbased learning were insignificant. This study conducted a meta-analysis of fourteen empirical studies related to web-based learning. One of the possible explanations for such results can be that certain features of web-based learning might decrease the gender gaps in cognitive process of information. Another explanation provided in their study was that gender differences are only observed when strong accumulating effects are given during the learning process. In addition, Al-Azawei (2019) only discovered slight gender differences in LMS acceptance levels. This study involved 302 undergraduate students in Iraq and utilized the extended Technology Acceptance Model (TAM) to predict learners' perceptions towards LMS adoption. It was found that female students were more concerned with ease of use, whereas male students were more concerned with technology usefulness. However, the differences were not significant. Thus, continuous research on gender effects should be carried out for clarification.

\section{Age and school year factors}

Although cultural factors and gender differences were suggested to play an important role in online learning and LMS implementation, previous studies have also shown that students' age can influence the learning outcomes. According to a study conducted by McSporran and Young (2001) in a first-year introductory course for the computing systems bachelor degree, older students are more motivated to learn, better at communicating online, and at organizing their learning schedules. In the same study, female students showed better performance than male students did. Hence, both gender and age factors were related to students' learning outcomes. 
As drawn from the literature review, four major factors could affect the dynamic process of smart learning through the operation of LMS. In addition, LMS requires students' active participation and engagement with learning because they often need to access online course materials without simultaneous prompting or instructions (Beer, Clark, \& Jones, 2010). This implies that students who largely depend on substantial instructor direction may struggle with LMS, as it demands a certain level of selfdiscipline (Douglas \& Alemanne, 2007). You (2016) also verified the importance of selfregulated learning in online courses based on LMS data measures from 530 college students. Thus, careful examinations of each influencing factor on LMS should be carried out in order to induce self-regulated learning and maximize the learning outcomes. As such, our study focuses on four important variables; 'cultural dimension' along with 'gender', 'age', and 'school year'. By analyzing students' preferred LMS functions or design, in relation to these four variables, the study results will extend current understanding of online learner preferences and provide useful guidance for smart learning environments, facilitated by LMS.

\section{Method}

\section{Study sample and context}

Fraenkel, Wallen, and Hyun (2012) have categorized case studies as intrinsic (detailed description of one context), instrumental (focusing on a case for comprehending a more detailed phenomenon) and collective (several different or similar cases scrutinized simultaneously), which may include "...one individual, classroom, school, or program..." (p. 435). Based on that description, this study falls under the definition of instrumental case study where the researchers have had an interest in understanding more than how some students value the importance of certain tools/elements for learning management system design. The researchers have been interested in a larger goal of understanding the role of the cultural dimension for learning management system design. Hence, the researchers who conducted this case study; have been more interested in revealing conclusions that could be implemented beyond a particular case than it is. Thus, this study aims to check the following hypotheses which were derived from the conclusions of the profound literature review:

- There is a statistically significant difference on each item of learning management design survey with respect to students' cultural background on being German versus Spanish.

- There is a statistically significant difference on each item of learning management design survey with respect to students' gender.

- There is a statistically significant difference on each item of learning management design survey with respect to students' age.

- There is a statistically significant difference on each item of learning management design survey with respect to students' school year.

The participants of this case study were comprised of German $(n=83)$ and Spanish ( $\mathrm{n}=83$ ) university students who were attending a fully online 'Management of Information Systems (MIS)' course provided by a South Korean university in Fall semester of 
2018. Both German and Spanish students utilized the same LMS which was delivered via the university in South Korea. The course took fifteen weeks and one of the researchers of this study was the course instructor of the online course. This course introduces students the basics of modern management information systems and how they have become an integral part of the global operations of the digital companies. The course begins with discussions on the potential of information systems and technologies in improving operational efficiency of common business processes and how they could be managed effectively. Information technology infrastructure, databases and telecommunications are covered earlier than digging deeper into enterprise, supplier and customer applications. Having gained some knowledge of a variety of MIS applications, the students are equipped with practical skills for selection, acquisition and deployment of different information systems, for which the course uses several case studies and exercises.

At the time of data collection, the students were already using the same Korean university LMS together for a month and these students used different LMS (similar features) in their educational lives previously. Additionally, Learning Management Systems (LMS) was one of the management information system applications within the course topics. Hence, the researchers safely assumed that the participants of these study have had enough knowledge on making personal judgement on the survey items.

At the end of week four, the students were given the prepared survey as a voluntary activity to be filled before week four. As Table 1 shows, majority of the participants (66\%) are in 18-25 age group and there is nearly an equal gender representation (53\% male and $47 \%$ female) for the participants.

Although there was an equal number of students for each country $(n=83$ for both Germany and Spain), there was diversity in school year (since the course was open for the registration to all school levels/years). Table 2 demonstrates that dominant groups were either freshman students (27\%) or master students $(28 \%)$.

\section{Study instrument}

The study instrument consists of four demographics related questions which were drawn from the literature review conclusions; gender (male or female), age (under 18, 18-25 or above 25), country (Germany or Spain) and school year (freshman, sophomore, junior, senior or master student). Afterwards, the researchers utilized the learning management design criteria of course textbook written by Laudon and Laudon (2018) to their survey (Table 3). Each category was marked on a five-point Likert scale

Table 1 Age versus gender characteristics of the participants

\begin{tabular}{llllll}
\hline Gender & & & Country & Total \\
\cline { 4 - 5 } & & & Germany & Spain & \\
\hline Male & Age Group & $18-25$ & 32 & 27 & 59 \\
& & Above 25 & 16 & 13 & 29 \\
& Total & 48 & 40 & 88 \\
Female & Age Group & $18-25$ & 24 & 27 & 51 \\
& & Above 25 & 11 & 16 & 27 \\
& & & 35 & 43 & 78 \\
\hline
\end{tabular}


Table 2 School year versus country data of the participants

\begin{tabular}{llll}
\hline School Year & Country & Total \\
\cline { 2 - 3 } & Germany & Spain & \\
\hline Freshman & 9 & 35 & $44(27 \%)$ \\
Sophomore & 17 & 11 & $28(17 \%)$ \\
Junior & 15 & 9 & $24(14 \%)$ \\
Senior & 14 & 9 & $23(14 \%)$ \\
Master & 28 & 19 & $47(28 \%)$ \\
Total & 83 & 83 & $166(100 \%)$ \\
\hline
\end{tabular}

from 'not important at all' to 'very important' where the students were grading the importance of each element for a learning management system. When the survey had been finalized, it was uploaded to a survey webpage and kept online for a week. The online survey was five webpage long where the first page was about students' four demographics and the rest was dedicated to each dimension in Table 3 separately.

\section{Data analysis}

The researchers conducted two crosstab analyses on the final dataset; 'age versus gender' and 'school year versus country'. Afterwards, the researchers applied normality test to the dataset on SPSS. Twenty items were checked against four demographic variables whether they show normal distribution on their levels. Both the Kolmogorov-Smirnov and Shapiro-Wilk tests rejected the null hypothesis of a normal population distribution for all four demographics $(p=0.05)$ (Denis, 2019). Therefore, the researchers decided to continue with non-parametric statistical techniques.

Additionally, the dataset was checked for its reliability. Twenty items were checked with one hundred sixty six participants and Cronbach alpha was calculated as 0.84 , which shows a good score for reliability. Since Cronbach's alpha does not assume normality (Sheng \& Sheng, 2012), there was no issue of use for that not-normally distributing dataset.

The researchers calculated the mean scores and standard deviations for twenty items in total, for German students only and for Spanish students only. The results were tabulated and commented accordingly. After these fundamental statistics, the comparison tests were conducted. First of all, three variables (age, gender and country) were checked for each of these twenty items by using Mann Whitney $U$ tests. The significant items were reported with their comments. Lastly, Kruskal Wallis $\mathrm{H}$ tests were conducted on twenty items for school year variable with its five levels; freshman,

Table 3 The LMS design criteria from Laudon and Laudon (2018)

\begin{tabular}{|c|c|c|c|}
\hline $\begin{array}{l}\text { Content Management } \\
\text { (6 items) }\end{array}$ & Ease of use ( 5 items) & $\begin{array}{l}\text { Communication } \\
\text { within the LMS } \\
\text { (4 items) }\end{array}$ & Design (5 items) \\
\hline $\begin{array}{l}\text { - Uploading assignments } \\
\text { - Reviewing grade } \\
\text { - Accessing learning } \\
\text { materials } \\
\text { - Comment feature } \\
\text { - Online whiteboard } \\
\text { - Private storage }\end{array}$ & $\begin{array}{l}\text { - Allowing downloading } \\
\text { multiple files } \\
\text { - Easy enrollment of subject } \\
\text { - Learning materials are } \\
\text { available before lectures } \\
\text { - Integrated offline mod } \\
\text { - Calendar integration }\end{array}$ & $\begin{array}{l}\text { - Chat system } \\
\text { - Discussion forum } \\
\text { - Survey feature } \\
\text { - Notifications }\end{array}$ & $\begin{array}{l}\text { - Simple navigation structure } \\
\text { - Choose a personal design/ } \\
\text { layout } \\
\text { - Mark files/courses as favorite } \\
\text { - Language selection } \\
\text { - Allowing access } \\
\text { through mobile application }\end{array}$ \\
\hline
\end{tabular}


sophomore, junior, senior and master students. The significant items were reported and mentioned accordingly.

\section{Results}

The total mean scores and standard deviations of each of the twenty design items were presented in Table $4(n=166)$. Additionally, the mean scores and standard deviations were calculated separately for German students $(n=83)$ and Spanish students $(n=83)$ and tabulated in Table 4. Within the 'content management' dimension, the highest means were observed for private storage $(M=3.82)$ and online whiteboard $(M=3.59)$. Integrated offline mode $(M=3.66)$ and calendar integration $(M=3.59)$ were revealed as the most valued items of 'ease of use' dimension. The dimension 'communication within the LMS' was calculated over 3.00 for each of its items; respectively chat system

Table 4 The mean scores and standard deviations of each of twenty items

\begin{tabular}{|c|c|c|c|c|c|c|c|}
\hline \multirow[t]{2}{*}{ Design Dimension } & \multirow[t]{2}{*}{ Design Items } & \multicolumn{2}{|c|}{$\begin{array}{l}\text { Total } \\
(n=166)\end{array}$} & \multicolumn{2}{|c|}{$\begin{array}{l}\text { German } \\
(\mathrm{n}=\mathbf{8 3})\end{array}$} & \multicolumn{2}{|c|}{$\begin{array}{l}\text { Spanish } \\
(\mathrm{n}=\mathbf{8 3})\end{array}$} \\
\hline & & $M$ & $S D$ & $M$ & $S D$ & $M$ & $S D$ \\
\hline \multirow{6}{*}{ Content Management } & Uploading assignments & 2.87 & 1.22 & 3.17 & 1.26 & 2.57 & 1.18 \\
\hline & Reviewing grade & 2.67 & 1.52 & 2.87 & 1.43 & 2.47 & 1.58 \\
\hline & Accessing learning materials & 2.87 & 1.32 & 3.46 & 1.09 & 2.29 & 1.28 \\
\hline & Comment feature & 2.90 & 1.63 & 2.41 & 1.47 & 3.40 & 1.64 \\
\hline & Online whiteboard & 3.59 & 1.66 & 2.78 & 1.65 & 4.40 & 1.22 \\
\hline & Private storage & 3.82 & 1.62 & 3.11 & 1.70 & 4.53 & 1.16 \\
\hline \multirow{5}{*}{ Ease of use } & $\begin{array}{l}\text { Allowing downloading multiple } \\
\text { files }\end{array}$ & 3.21 & 1.67 & 3.11 & 1.43 & 3.31 & 1.87 \\
\hline & Easy enrollment of subject & 3.19 & 1.53 & 2.65 & 1.27 & 3.73 & 1.58 \\
\hline & $\begin{array}{l}\text { Learning materials are available } \\
\text { before lectures }\end{array}$ & 2.58 & 1.47 & 2.88 & 1.52 & 2.28 & 1.36 \\
\hline & Integrated offline mod & 3.66 & 1.69 & 3.15 & 1.73 & 4.18 & 1.49 \\
\hline & Calendar integration & 3.59 & 1.65 & 2.96 & 1.60 & 4.22 & 1.46 \\
\hline \multirow{4}{*}{$\begin{array}{l}\text { Communication within } \\
\text { the LMS }\end{array}$} & Chat system & 3.54 & 1.72 & 3.04 & 1.72 & 4.04 & 1.58 \\
\hline & Discussion forum & 3.33 & 1.67 & 2.88 & 1.49 & 3.80 & 1.72 \\
\hline & Survey feature & 3.24 & 1.72 & 2.88 & 1.63 & 3.60 & 1.75 \\
\hline & Notifications & 3.42 & 1.68 & 2.90 & 1.59 & 3.93 & 1.62 \\
\hline \multirow{5}{*}{ Design } & Simple navigation structure & 2.51 & 1.31 & 2.86 & 1.36 & 2.16 & 1.15 \\
\hline & Choose a personal design/layout & 3.78 & 1.62 & 3.13 & 1.72 & 4.42 & 1.22 \\
\hline & Mark files/courses as favorite & 3.82 & 1.53 & 3.23 & 1.54 & 4.41 & 1.27 \\
\hline & Language selection & 3.06 & 1.38 & 3.17 & 1.45 & 2.95 & 1.32 \\
\hline & $\begin{array}{l}\text { Allowing access through mobile } \\
\text { application }\end{array}$ & 3.00 & 1.50 & 3.01 & 1.55 & 2.99 & 1.46 \\
\hline
\end{tabular}


$(M=3.54)$, notifications $(M=3.42)$, discussion forum $(M=3.33)$ and survey feature $(\mathrm{M}=3.24)$. For the last dimension of screen 'design', the participants mostly valued marking files/courses as their favorites $(M=3.82)$ and choosing a personal layout $(\mathrm{M}=3.78)$.

When the mean scores of each country were considered, it is easy to see that many design items were valued differently. Thirteen items were more valued by Spanish students and seven items were more valued by German students. The higher mean score for each item was highlighted grey in Table 4. The simple mean score differences may not show the real statistically differentiating items. Therefore, the comparison tests of Mann-Whitney $\mathrm{U}$ tests and Kruskal Wallis $\mathrm{H}$ tests were run for better understanding.

First Mann-Whitney U tests were conducted for gender variable (male versus female) on twenty items of learning management system design. The only significantly differentiating item was appeared on the first item of 'ease of use' dimension; 'allowing downloading multiple files' $(U=2811.500, p=0.037)$. The mean rank demonstrated that male students (mean rank $=90.55, n=88$ ) valued the downloading multiple files feature more than female students do (mean rank $=75.54, n=78$ ).

Other Mann-Whitney U tests were implemented for age variable (18-25 versus above 25 ) on twenty learning management system design items. The results yielded only one single significantly differentiating item which belongs to 'communication within the LMS' dimension; 'survey feature' $(U=2450.000, p=0.023)$. The mean rank for 'above 25 ' group $(n=56)$ is higher than ' $18-25$ ' age group $(n=110) ; 94.75$ and 77.77 respectively.

The last Mann-Whitney $U$ tests were run for the country variable (Germany versus Spanish). As Table 5 demonstrates, sixteen items were significantly differentiated around country variable. Among these sixteen significantly differentiating items, only four design items' mean ranks were higher for German students; 'uploading assignments', 'accessing learning materials', 'learning materials are available before lectures' and 'simple navigation structure'. The Spanish students' mean ranks were higher than German students for the other twelve design items; 'comment feature', 'online whiteboard', 'private storage', 'easy enrollment of subject', 'integrated offline mod', 'calendar integration', 'chat system', 'discussion forum', 'survey feature', 'notifications', 'choose a personal design/layout', and 'mark files/courses as favorite'.

The last comparison tests were conducted on the school year variable for twenty design items separately. The Kruskal Wallis $\mathrm{H}$ tests results unfolded eleven significantly differentiating design items around the school year variable; 'comment feature', 'online whiteboard', 'private storage', 'allowing downloading multiple files', 'learning materials are available before lectures', 'calendar integration', 'discussion forum', 'survey feature', 'notifications', 'choose a personal design/layout' and 'mark files/courses as favorite'. Although the number of students in each school level differs from each other, the mean ranks could still be used to get a deeper understanding for school years on each design item. Table 6 shows that except 'learning materials are available before lectures' design items where the master students had the highest mean rank, freshman students' mean ranks were the highest for the other ten significantly differentiating design items.

\section{Discussion and conclusion}

As LMS has become a crucial element of different instructional contexts, the efforts trying to unfold its successful design factors have been studied more than ever before. 
Table 5 The Mann-Whitney $U$ tests results for the country variable

\begin{tabular}{|c|c|c|c|c|c|}
\hline Design Dimension & Design Items & Mann-Whitney U & $p$ & Country & $\begin{array}{l}\text { Mean } \\
\text { Rank }\end{array}$ \\
\hline \multirow[t]{11}{*}{ Content Management } & \multirow[t]{2}{*}{ Uploading assignments } & \multirow[t]{2}{*}{2469.000} & \multirow[t]{2}{*}{.001} & Germany $(n=83)$ & 95.25 \\
\hline & & & & Spain $(n=83)$ & 71.75 \\
\hline & Reviewing grade & 2928.500 & .085 & Not significant & \\
\hline & \multirow[t]{2}{*}{ Accessing learning materials } & \multirow[t]{2}{*}{1759.000} & \multirow[t]{2}{*}{.000} & Germany ( $n=83)$ & 103.81 \\
\hline & & & & Spain $(n=83)$ & 63.19 \\
\hline & \multirow[t]{2}{*}{ Comment feature } & \multirow[t]{2}{*}{2268.000} & \multirow[t]{2}{*}{.000} & Germany ( $n=83$ ) & 69.33 \\
\hline & & & & Spain $(n=83)$ & 97.67 \\
\hline & \multirow[t]{2}{*}{ Online whiteboard } & \multirow[t]{2}{*}{1608.000} & \multirow[t]{2}{*}{.000} & Germany $(n=83)$ & 61.37 \\
\hline & & & & Spain $(n=83)$ & 105.63 \\
\hline & \multirow[t]{2}{*}{ Private storage } & \multirow[t]{2}{*}{1799.500} & \multirow[t]{2}{*}{.000} & Germany ( $\mathrm{n}=83$ ) & 63.68 \\
\hline & & & & Spain $(n=83)$ & 103.32 \\
\hline \multirow[t]{9}{*}{ Ease of use } & $\begin{array}{l}\text { Allowing downloading } \\
\text { multiple files }\end{array}$ & 3033.000 & .167 & Not significant & \\
\hline & \multirow[t]{2}{*}{ Easy enrollment of subject } & \multirow[t]{2}{*}{2035.500} & \multirow[t]{2}{*}{.000} & Germany $(n=83)$ & 66.52 \\
\hline & & & & Spain $(n=83)$ & 100.48 \\
\hline & \multirow{2}{*}{$\begin{array}{l}\text { Learning materials are } \\
\text { available before lectures }\end{array}$} & \multirow[t]{2}{*}{2662.500} & \multirow[t]{2}{*}{.009} & Germany ( $n=83$ ) & 92.92 \\
\hline & & & & Spain $(n=83)$ & 74.08 \\
\hline & \multirow[t]{2}{*}{ Integrated offline mod } & \multirow[t]{2}{*}{2265.000} & \multirow[t]{2}{*}{.000} & Germany $(n=83)$ & 69.29 \\
\hline & & & & Spain $(n=83)$ & 97.71 \\
\hline & \multirow[t]{2}{*}{ Calendar integration } & \multirow[t]{2}{*}{1876.000} & .000 & Germany $(n=83)$ & 64.60 \\
\hline & & & & Spain $(n=83)$ & 102.40 \\
\hline Communication & Chat system & 2322.500 & .000 & Germany $(n=83)$ & 69.98 \\
\hline & & & & Spain $(n=83)$ & 97.02 \\
\hline & Discussion forum & 2314.500 & .000 & Germany $(n=83)$ & 69.89 \\
\hline & & & & Spain $(n=83)$ & 97.11 \\
\hline & Survey feature & 2629.500 & .005 & Germany $(n=83)$ & 73.68 \\
\hline & & & & Spain $(n=83)$ & 93.32 \\
\hline & Notifications & 2180.000 & .000 & Germany $(n=83)$ & 68.27 \\
\hline & & & & Spain $(n=83)$ & 98.73 \\
\hline Design & Simple navigation structure & 2418.000 & .001 & Germany $(n=83)$ & 95.87 \\
\hline & & & & Spain $(n=83)$ & 71.13 \\
\hline & Choose a personal & 2015.000 & .000 & Germany $(n=83)$ & 66.28 \\
\hline & & & & Spain $(n=83)$ & 100.72 \\
\hline & Mark files/courses as favorite & 1888.000 & .000 & Germany $(n=83)$ & 64.75 \\
\hline & & & & Spain $(n=83)$ & 102.25 \\
\hline & Language selection & 3157.500 & .342 & Not significant & \\
\hline & $\begin{array}{l}\text { Allowing access through } \\
\text { mobile application }\end{array}$ & 3426.500 & .953 & Not significant & \\
\hline
\end{tabular}

The previous studies enlisted four essential success factors for LMS implementations. Therefore, this study aims to understand LMS design from a cultural point of view in additional variables of gender, age and school year. The general results clearly demonstrated that one unique LMS design will not be useful and appreciated by the students all the time. In that sense, other than setting up a commonly designed LMS on their 
Table 6 The Kruskal Wallis $\mathrm{H}$ tests results for the school year variable

\begin{tabular}{|c|c|c|c|c|c|c|}
\hline Design Dimension & Design Items & $\mathrm{X}^{2}(4)$ & $p$ & School Year & $\mathrm{n}$ & Mean Rank \\
\hline \multirow{18}{*}{$\begin{array}{l}\text { Content } \\
\text { Management }\end{array}$} & Uploading assignments & \multicolumn{5}{|c|}{ Not significant } \\
\hline & Reviewing grade & \multicolumn{5}{|c|}{ Not significant } \\
\hline & Accessing learning materials & \multicolumn{5}{|c|}{ Not significant } \\
\hline & \multirow[t]{5}{*}{ Comment feature } & \multirow[t]{5}{*}{11.780} & \multirow[t]{5}{*}{.019} & freshman & 44 & 100.26 \\
\hline & & & & sophomore & 28 & 87.41 \\
\hline & & & & junior & 24 & 76.88 \\
\hline & & & & senior & 23 & 61.65 \\
\hline & & & & master & 47 & 79.55 \\
\hline & \multirow[t]{5}{*}{ Online whiteboard } & \multirow[t]{5}{*}{14.108} & \multirow[t]{5}{*}{.007} & freshman & 44 & 102.36 \\
\hline & & & & sophomore & 28 & 70.98 \\
\hline & & & & junior & 24 & 66.52 \\
\hline & & & & senior & 23 & 86.35 \\
\hline & & & & master & 47 & 80.57 \\
\hline & \multirow[t]{5}{*}{ Private storage } & \multirow[t]{5}{*}{10.341} & \multirow[t]{5}{*}{.035} & freshman & 44 & 100.61 \\
\hline & & & & sophomore & 28 & 77.20 \\
\hline & & & & junior & 24 & 71.48 \\
\hline & & & & senior & 23 & 79.33 \\
\hline & & & & master & 47 & 79.41 \\
\hline \multirow[t]{17}{*}{ Ease of use } & \multirow{5}{*}{$\begin{array}{l}\text { Allowing downloading } \\
\text { multiple files }\end{array}$} & \multirow[t]{5}{*}{17.738} & \multirow[t]{5}{*}{.001} & freshman & 44 & 104.56 \\
\hline & & & & sophomore & 28 & 83.59 \\
\hline & & & & junior & 24 & 57.52 \\
\hline & & & & senior & 23 & 73.96 \\
\hline & & & & master & 47 & 81.67 \\
\hline & Easy enrollment of subject & \multicolumn{2}{|c|}{ Not significant } & & & \\
\hline & \multirow{5}{*}{$\begin{array}{l}\text { Learning materials are } \\
\text { available before lectures }\end{array}$} & \multirow[t]{5}{*}{10.781} & \multirow[t]{5}{*}{.029} & freshman & 44 & 85.14 \\
\hline & & & & sophomore & 28 & 66.91 \\
\hline & & & & junior & 24 & 68.23 \\
\hline & & & & senior & 23 & 87.20 \\
\hline & & & & master & 47 & 97.84 \\
\hline & Integrated offline mod & \multicolumn{2}{|c|}{ Not significant } & & & \\
\hline & \multirow[t]{5}{*}{ Calendar integration } & 11.774 & .019 & freshman & 44 & 102.26 \\
\hline & & & & sophomore & 28 & 73.88 \\
\hline & & & & junior & 24 & 85.23 \\
\hline & & & & senior & 23 & 73.17 \\
\hline & & & & master & 47 & 75.84 \\
\hline Communication & Chat system & Not sign & ficant & & & \\
\hline WIthin the LIVIS & Discussion forum & 15.135 & .004 & freshman & 44 & 103.95 \\
\hline & & & & sophomore & 28 & 73.18 \\
\hline & & & & junior & 24 & 83.67 \\
\hline & & & & senior & 23 & 86.57 \\
\hline & & & & master & 47 & 68.91 \\
\hline & Survey feature & 11.756 & .019 & freshman & 44 & 101.22 \\
\hline & & & & sophomore & 28 & 80.14 \\
\hline & & & & junior & 24 & 66.65 \\
\hline
\end{tabular}


Table 6 The Kruskal Wallis $\mathrm{H}$ tests results for the school year variable (Continued)

\begin{tabular}{|c|c|c|c|c|c|c|}
\hline Design Dimension & Design Items & $x^{2}(4)$ & $p$ & School Year & $\mathrm{n}$ & Mean Rank \\
\hline & & & & senior & 23 & 71.39 \\
\hline & & & & master & 47 & 83.45 \\
\hline & Notifications & 12.566 & .014 & freshman & 44 & 103.43 \\
\hline & & & & sophomore & 28 & 76.00 \\
\hline & & & & junior & 24 & 68.98 \\
\hline & & & & senior & 23 & 81.39 \\
\hline & & & & master & 47 & 77.76 \\
\hline \multirow[t]{13}{*}{ Design } & Simple navigation structure & \multicolumn{2}{|c|}{ Not significant } & & & \\
\hline & \multirow[t]{5}{*}{ Choose a personal design/layout } & 17.027 & .002 & freshman & 44 & 105.68 \\
\hline & & & & sophomore & 28 & 77.57 \\
\hline & & & & junior & 24 & 81.33 \\
\hline & & & & senior & 23 & 72.30 \\
\hline & & & & master & 47 & 72.85 \\
\hline & \multirow[t]{5}{*}{ Mark files/courses as favorite } & 22.935 & .000 & freshman & 44 & 108.78 \\
\hline & & & & sophomore & 28 & 75.13 \\
\hline & & & & junior & 24 & 84.46 \\
\hline & & & & senior & 23 & 77.57 \\
\hline & & & & master & 47 & 67.23 \\
\hline & Language selection & \multicolumn{2}{|c|}{ Not significant } & & & \\
\hline & $\begin{array}{l}\text { Allowing access through } \\
\text { mobile application }\end{array}$ & \multicolumn{2}{|c|}{ Not significant } & & & \\
\hline
\end{tabular}

school smart systems, the managers/instructors should prefer a more user centered approach where the LMS will be tailored according to their students' demographics (especially the variables discussed in this study).

When German and Spanish students were compared with non-parametric statistical tests, it seemed that Spanish students generally more valued various features of LMS. In particular, Spanish students claimed that ease of use and communication within the LMS are important features for their learning. In the content management section, Spanish students also valued comment feature and online whiteboard as evident in the mean scores and the Mann-Whitney $U$ test results. This implies that Spanish students would prefer learning through communication. Hence, the instructional designers or practitioners should offer more interactive and communicative opportunities to Spanish students on their LMS.

On the other hand, German students have put a strong emphasis on LMS features such as 'uploading assignments', 'accessing learning materials', 'learning materials are available before lectures' and 'simple navigation structure'. Most of these features are directly related to the final grade and individual learning. Such different characteristics of German and Spanish students could affect their learning behaviors in a way that German students would value goal-oriented individual learning and Spanish students would value process-oriented group learning with active communication. This gives clues to the instructors while designing their instructional activities on LMS. For instance, Spanish students should be directed toward more group assignments whereas German students would appreciate more individual self-studies and exercises. 
In fact, this study results are relevant to a four-dimensional model of cultural differences proposed by Hofstede (1986). Based on Hofstede's model, the individualismcollectivism dimension provides a possible explanation for different characteristics of German and Spanish students. As described by Mercado et al. (2004), individualism values personal achievement or well-being of an individual, which suits with the characteristics observed from German students. On the other hand, collectivism highlights group achievement or group actions, which can match with the characteristics shown by Spanish students. These findings can also explain both countries' different cultural dimension scores on individualism versus collectivism as mentioned in the literature review (Hofstede et al., 2010). As German students highly valued two LMS features, 'accessing learning materials' and 'learning materials are available before lectures', it implies that German students want to be prepared for their classes. Such preparation might be related to uncertainty avoidance for what they will learn in class. If so, it will contradict the results obtained by Hofstede et al. (2010) as Germany's uncertainty avoidance score was lower than Spain. Therefore, the fundamental reason for accessing learning materials should be clarified to further explain such contradictory results. The remaining two cultural dimensions, power distance and masculinity, could not be related to our study results as students' perspectives on hierarchical learning and competition-based learning were not assessed. Despite the cultural differences, it should be also noted that both groups of students similarly valued certain features of LMS such as reviewing grade, downloading multiple files, language selection, and access through mobile application. In both cultures, the LMS features related to users' convenience seem equally important.

In this study, significant gender differences were not observed. The only difference observed was that male students valued downloading multiple files feature of LMS more than female students, which could mean male students favor efficiency when using LMS. As suggested by Astleitner and Steinberg (2005), LMS features might actually reduce gender differences compared to the offline class environments or there were not enough accumulating effects to induce gender differences in our study. Another possible explanation could be that gender differences are created due to the learning materials or course contents rather than LMS itself. Further elucidation on gender effect is required in future studies.

In terms of the age variable, this study results indicated that higher age group students more valued communication within the LMS, in particular, survey feature. This result is also supported by McSporran and Young (2001) as their study showed better communication skills from older students. As a learner's age increases, it might also develop online/offline communication skills and thus learning through communication becomes a preferable option. However, it should be noted that communication features of LMS were not necessarily valued by students with the higher school year. In other words, the school year variable does not induce the same effect on the learning process or learning preference as the age variable does. Therefore, instructors should not assume similar learning behaviors between the higher age group and higher school year group when designing and implementing an LMS.

When the school year variable was examined, numerous features of LMS were highly valued by the freshman students. One of the possible reasons would be an exposure to new smart learning environments. As freshman students need to adapt in the university 
education system, they need to pay a particular attention to each element of an LMS. Once the adaptation period is over, the significance of LMS features might be reduced and students will gradually utilize specific LMS functions that are directly relevant to their learning process. Indeed, each feature of LMS was valued differently in each school year apart from the freshman period. It is interesting to note that the master students highly valued availability of the learning materials before lectures. This possibly indicates that postgraduate programs emphasize more on pre-class learning, which is often observed in learner-centered environments.

Our study explored various features of LMS valued by different groups of students based on their cultural background, gender, age, and school year. Out of the four hypotheses tested in our study, the first (cultural background) and the fourth (school year) hypotheses were validated whereas the second (gender) and the third (age) hypotheses were partially validated. Although not every hypothesis was fully validated, there are several important recommendations for instructors or education providers based on our study results. First of all, it is advised that future LMS design should consider the four-dimensional model of Hofstede (1986), especially the individualismcollectivism dimension to cater for various learning needs of international students. Understanding the effect of culture on LMS design, delivery and implementation will provide more user satisfaction leading toward more success stories in education. Secondly, learning materials on LMS should be checked for possible inducing factors of gender differences. In that sense, the instructors should be informed about gender bias issues. Thirdly, more communication features of LMS will be effective in the courses with higher age groups. Lastly, LMS can provide more guidelines or assistance for freshman students and create a wide range of learner-centered environments for postgraduate programs.

Since this study was delimited to two specific cultures, prospective studies must focus on adding more variety to similar culture based design studies. In order to gain a further understanding of LMS and smart learning process, future studies should investigate more various cultural groups and their learning characteristics. Moreover, due to the sample limitation of this study, the researchers highly recommend to conduct prospective studies with larger sample size to analyze group with parametric techniques. If possible and available, students' LMS logs (including the most commonly used tools) should be analyzed for a better understanding of LMS tools and their usage by different cultures. Similarly, different variables examined in this study could be compared with assessment or examination grades to identify which LMS features can maximize the learning outcomes for a particular group of students. Additionally, qualitative interview schedules should be integrated into culture based studies to understand its effects in depth.

Since this study implemented the convenience sampling which might have the disadvantage of bias, the similar studies should be replicated in different courses or universities to check if the observed results are due to onetime occurrence. Moreover, LMS has also been utilized in business world where different companies' training activities are supported by these smart systems. In that sense, the research in business world could assist us to understand the deeper influence of culture.

The instructional stakeholders must always remember that future studies on culturally sensitive LMS design will contribute to the achievement of better learning in the waves of upcoming digital revolution era. 
Abbreviations

LMS: Learning management systems; MBA: Master of business administration; MIS: Management of information systems

\section{Acknowledgements}

Not applicable.

\section{Authors' contributions}

Hasan Tinmaz was responsible from method and results sections. Jin Hwa Lee was in charge of literature review and discussion sections. The authors worked together on the rest of the manuscript. The authors read and approved the final manuscript.

\section{Funding}

Authors declare that no funding for the research was provided from any side.

\section{Availability of data and materials}

The corresponding author declared here all types of data used in this study available for any clarification. The author of this manuscript ready for any justification regarding the data set. To make publically available of the data used in this study, the seeker must send an email to the mentioned email address. The profile of the respondents was completely confidential.

\section{Competing interests}

The authors declare that they have no competing interests.

\section{Author details}

${ }^{1}$ Technology Studies, Endicott College of International Studies, Woosong University, Daejeon, South Korea. ${ }^{2}$ Global Healthcare Management, Sol International School, Woosong University, 171 Dongdaejeon-ro, Dong-gu, Daejeon 34606, South Korea.

Received: 13 April 2020 Accepted: 30 September 2020

Published online: 14 October 2020

\section{References}

Adamus, T., Kerres, M., Getto, B., \& Engelhardt, N. (2009). Gender and e-tutoring - A concept for gender sensitive e-tutor training programs. In Fifth European symposium on gender \& ICT digital cultures: Participation - empowerment - diversity. University of Bremen March 5-7, 2009 - Retrieved from http://www.informatik.uni-bremen.de/soteg/gict2009/ proceedings/GICT2009_Adamus.pdf.

Al-Azawei, A. (2019). The moderating effect of gender differences on learning management system acceptance: A multigroup analysis. Italian Journal of Educational Technology, 27(3), 257-278. https://doi.org/10.17471/2499-4324/1088.

Astleitner, H., \& Steinberg, R. (2005). Are there gender differences in web-based learning? An integrated model and related effect sizes. Association for the Advancement of Computing in Education, 13(1), 47-63.

Asunka, S. (2016). Helping faculty overcome cultural barriers to adoption and use of web-based learning technologies: A participatory action research approach. In Revolutionizing education through web-based instruction, (pp. 300-316).

Beer, C., Clark, K., \& Jones, D. (2010). Indicators of engagement. In Proceedings Ascilite Sydney 2010, (pp. 75-86) Retrieved from http://ascilite.org.au/conferences/sydney10/procs/Beer-full.pdf.

Bove, L., \& A., \& Conklin, S. (2020). Learning strategies for faculty during a learning management system migration. Online Journal of Distance Learning Administration, 23(1), 1-10.

Bruestle, P., Haubner, D., Schinzel, B., Holthaus, M., Remmele, B., Schirmer, D., \& Reips, U. D. (2009). Doing e-learning/doing gender? Examining the relationship between students' gender concepts and e-learning technology. In Fifth European symposium on gender \& ICT digital cultures: Participation - empowerment - diversity. University of Bremen March 5-7, 2009. Retrieved from http://www.informatik.uni-bremen.de/soteg/gict2009/proceedings/GICT2009_Adamus.pdf.

Cuadrado-García, M., Ruiz-Molina, M. E., \& Montoro-Pons, J. D. (2010). Are there gender differences in e-learning use and assessment? Evidence from an interuniversity online project in Europe. Procedia - Social and Behavioral Sciences, 2(2), 367-371. https://doi.org/10.1016/j.sbspro.2010.03.027.

Denis, D. J. (2019). SPSS data analysis for univariate, bivariate, and multivariate statistics. Hoboken: Wiley.

Douglas, I., \& Alemanne, N. D. (2007). Measuring student participation and effort. Algarve: Paper presented at the international conference on cognition and exploratory learning in digital age Retrieved from https://www.researchgate.net/ publication/241134504_Measuring_student_participation_and_effort.

Fraenkel, J. R., Wallen, N. E., \& Hyun, H. H. (2012). How to design and evaluate research in education, (8th ed., ). New York: McGraw-Hill Humanities/Social Sciences/Languages.

Hofstede, G. (1986). Cultural differences in teaching and learning. International Journal of Intercultural Relations, 10(3), 301-320. https://doi.org/10.1016/0147-1767(86)90015-5.

Hofstede, G., Hofstede, G. J., \& Minkov, M. (2010). Cultures and organizations: Software of the mind. Revised and expanded, (3rd ed., ). New York: McGraw-Hill.

Hunt, A., \& Tickner, S. (2015). Cultural dimensions of learning in online teacher education courses. Journal of Open, Flexible, and Distance Learning, 19(2), 25-47.

Laudon, K. C., \& Laudon, J. P. (2018). Management information systems: Managing the digital firm, (15th ed., ). New York: Pearson.

Lim, K., \& Meier, E. B. (2011). Different but similar: Computer use patterns between young Korean males and females. Educational Technology Research and Development, 59(4), 575-592. https://doi.org/10.1007/s11423-011-9206-5.

Liu, X., Liu, S., Lee, S. H., \& Magjuka, R. J. (2010). Cultural differences in online learning: International student perceptions. Journal of Educational Technology \& Society, 13(3), 177-188. 
McSporran, M., \& Young, S. (2001). Does gender matter in online learning? Unitec New Zealand working paper. Retrieved from https://repository.alt.ac.uk/348/1/ALT_J_Vol9_No2_2001_Does\%20gender\%20matter\%20in\%20online\%20l.pdf.

Mercado, S., Parboteeah, K. P., \& Zhao, Y. (2004). On-line course design and delivery: Cross-national considerations. Strategic Change, 13(4), 183-192. https://doi.org/10.1002/jsc.677.

Parrish, P., \& Linder-VanBerschot, J. A. (2010). Cultural dimensions of learning: Addressing the challenges of multicultural instruction. International Review of Research in Open and Distance Learning, 11(2), 1-19. https://doi.org/10.19173/irrodl. V11i2.809.

Sheng, Y., \& Sheng, Z. (2012). Is coefficient alpha robust to non-normal data? Frontiers in Psychology, 3(34). https://doi.org/10. 3389/fpsyg.2012.00034.

Swierczek, F. W., \& Bechter, C. (2010). Cultural features of e-learning: A euro Asian case study. In J. M. Spector et al. (Eds.), Learning and instruction in the digital age, (pp. 291-308). New York: Springer.

Tarhini, A., Hone, K., Liu, X., \& Tarhini, T. (2017). Examining the moderating effect of individual-level cultural values on users' acceptance of e-learning in developing countries: A structural equation modeling of an extended technology acceptance model. Interactive Learning Environments, 25(3), 306-328. https://doi.org/10.1080/10494820.2015.1122635.

Yakubu, M. N. (2019). The effect of quality antecedents on the acceptance of learning management systems: A case of two private universities in Nigeria. International Journal of Education and Development using Information and Communication Technology, 15(4), 101-115

You, J. W. (2016). Identifying significant indicators using LMS data to predict course achievement in online learning. The Internet and Higher Education, 29, 23-30.

\section{Publisher's Note}

Springer Nature remains neutral with regard to jurisdictional claims in published maps and institutional affiliations.

\section{Submit your manuscript to a SpringerOpen ${ }^{\circ}$ journal and benefit from:}

- Convenient online submission

- Rigorous peer review

- Open access: articles freely available online

High visibility within the field

- Retaining the copyright to your article

Submit your next manuscript at $\boldsymbol{\nabla}$ springeropen.com 